\title{
Predictors of Intention to Obtain HPV Vaccination among Thai Female College Students
}

\author{
Sukmadewi SUKMADEWI ${ }^{1}$, Kamonthip WIWATTANAWONGSA ${ }^{1, *}$, \\ Sopen CHUNUAN ${ }^{2}$ and Aris WIDAYATI ${ }^{3}$
}

\author{
${ }^{I}$ Department of Clinical Pharmacy, Faculty of Pharmaceutical Sciences, Prince of Songkla University, \\ Songkhla 90110, Thailand \\ ${ }^{2}$ Department of Maternal and Newborn Nursing and Midwifery, Faculty of Nursing, \\ Prince of Songkla University, Songkhla 90110, Thailand \\ ${ }^{3}$ Department of Social, Behavioral, and Administrative Pharmacy, Faculty of Pharmacy, \\ Sanata Dharma University, Yogyakarta, Indonesia
}

('Corresponding author's e-mail: kamonthip.w@psu.ac.th)

Received: 2 July 2020, Revised: 7 January 2021, Accepted: 14 January 2021

\begin{abstract}
This study determined the predictors of intention to obtain HPV vaccination among Thai female college students. The participants of this study were Thai female college students aged 18 - 26 years who were unvaccinated $(\mathrm{N}=191)$. The study used a cross-sectional survey conducted from October to November of 2018. Seven predictors were included in the conceptual framework and analyzed for their relative contribution using multiple regression. The questionnaire reliability was $>0.80$ for each construct, except knowledge (0.714). Significant predictors for intention to obtain HPV vaccine were found to be attitude to obtain HPV vaccination $(\beta=0.31, \mathrm{p}<0.001)$; perceived behavioral control $(\beta=$ $0.31, \mathrm{p}<0.001)$; and perceived susceptibility $(\beta=0.22, \mathrm{p}=0.005)$, accounting for $40 \%$ of its variance. Increasing intention to obtain the vaccine of HPV among Thai female college students should focus on enhancing positive attitudes toward obtaining the HPV vaccination, boosting perceived behavioral control, and increasing perceived susceptibility to its infection and diseases.
\end{abstract}

Keywords: College women, Human papillomavirus, Intention, Immunizations

\section{Introduction}

In 2018, new cervical cancer cases were found in 570,000 women from developing regions of the world [1]. Approximately 8,622 of these new cases arose in Thailand, ranking as the $4^{\text {th }}$ highest agestandardized incidence of cervical cancer in South-East Asia [2]. In the next 10 to 20 years, 11 million women will be diagnosed with cervical cancer, with $84 \%$ of the new cases and up to $90 \%$ deaths occurring in low- and middle-income countries [3]. In addition, over 4,947 cervical cancer deaths were of Thai women aged 15 to 44 years, making cervical cancer as the $4^{\text {th }}$ leading cause of cancer death [2].

Cervical cancer is developed by persistent infection of human papillomavirus (HPV) [4]. Infections of genotype 16 and 18 were most frequently found in cervical lesions [5]. Of the 4 Thai regions analyzed, the highest HPV infection prevalence was found in the southern region (97.10\%) [5]. It was estimated that more than $25 \%$ of HPV infections occurred among women aged 20 - 30 years, proportionately the highest among all of the age groups [6]. Specifically, college women are at high risk of HPV infection. Women enrolled in college tend to be vulnerable to various risk factors, including physiological, psychosocial, and behavioral factors, which make them susceptible to acquiring HPV [7,8]. College women who did not use condoms in their last sexual intercourse and had $\geq$ three sexual partners showed a 
higher potential of acquiring HPV [9]. The strongest sexual risk factor is having a laboratory documented sexually transmitted infection (STIs) [10].

In 2014, cervical cancer prevention programs began in Thailand through school-based human papillomavirus (HPV) vaccination [11]. Female students in grade 5 have been given the right to receive the vaccination for free [11]. HPV vaccination age between 9 and 13 was recommended by World Health Organization (WHO). While the age recommended by the Advisory Committee on Immunization Practices (ACIP), for HPV vaccination has been extended to 26 years, particularly if they had not previously been vaccinated and were sexually active [12,13]. As the risk of infection is highest in the age group of 18 - 30 years old, the HPV vaccine could give a benefit [14]. HPV vaccination on these group would lower the concern of the duration of vaccination protection [14]. However, it is not yet clear if perceptions of vaccine effectiveness are a predictor for intention to obtaining HPV vaccine among Thai women.

The United Nations Educational, Scientific and Cultural Organization (UNESCO) reported that $4,871,711$ Thai people aged 18 to 22 years pursue tertiary education [15]. In 2016, females accounted for a higher ratio of gross enrollment than males $(57.75 \%$ females, $41.06 \%$ males). The increasing trend of female college student enrollment since 2008 presents an opportunity to extend the uptake of HPV vaccination in a high-risk population to those qualified for the vaccine. It is vital to comprehend intention, which has been proven to play a role as an antecedent of vaccinating behavior, to boost the uptake of HPV vaccination in the unvaccinated group [16,17]. Thus, understanding the significant factors that influence intention based on behavioral theory is worthwhile to increase intention [18].

Two studies have investigated factors affecting intention toward HPV vaccination in Thai college women [19,20]. However, both studies included participants who are students from health-science programs $[19,20]$. These participants have been proven to possess a higher level of HPV knowledge, partly due to their greater exposures to diseases-related information. Accessibility to this information among students in non-health-related programs was inconsistent [21]. Consequently, there seems to exist a scope to gain more understanding of the intention to obtain the HPV vaccine in this population. Moreover, the number of Thai female college students who had high and low intention to obtain HPV vaccines were indifferent $[19,20]$. Therefore, this study aimed to determine significant predictors for obtaining HPV vaccine intentions among Thai female college students.

\section{Materials and methods}

\section{Methods}

To address the significant predictors of intention, the concept of TPB was implemented with three main constructs: Attitude to obtain HPV vaccination, subjective norm to obtain HPV vaccination, and perceived behavioral control to obtain HPV vaccination, as well as knowledge of HPV and cervical cancer. A theory of planned behavior (TPB) explains the attitude toward the behavior, subjective norm, and perceived behavioral control acts as a direct predictor of intention, while knowledge acts as an indirect predictor [16]. TPB has been employed in several studies on predictors of young women's vaccine intention [22-25].

The following three factors were also evaluated by their perceived susceptibility in not obtaining HPV vaccination, cost of HPV vaccination, as well as the perceived effectiveness of the vaccine. The other conceptual framework, Health belief model (HBM) has been used in a number of studies involving intention [19,26]. Four components of HBM: 'perceived susceptibility', 'perceived effectiveness', 'perceived barrier' and cues to action are determinants of vaccination behavior [27]. For vaccination, 'perceived susceptibility' has appeared as a predictor of vaccination intention [19]. While 'perceived effectiveness' was the most important determinant for intention among Canadian college women, according to HBM [22]. One common reason that college women in the US did not intend to obtain the HPV vaccination was the cost of the vaccine [17]. Likewise, it has been pointed out that 'perceived susceptibility' and 'cost of the vaccines' were the common reasons why Thai college women refused to be vaccinated [20]. 


\section{Participants}

This descriptive cross-sectional study was conducted in two universities located in the south of Thailand; Prince of Songkla University (PSU) and Songkhla Rajabhat Univeristy (SKRU), where the student body is diverse. Female undergraduate students aged 18 to 26, from 10 non-health science faculties were enrolled. According to the benchmarks, sample size calculation was medium effect size (0.35), power of 0.95 with $\alpha=0.05$ and 7 predictors. Seventy participants were required for multiple linear regression based on $\mathrm{G}^{*}$ Power calculation. However, a minimum of 179 participants were needed for the normality test. The inclusion criteria for the study were undergraduate students in non-healthrelated faculty aged 18 - 26 years from PSU-Hat Yai and Songkhla Rajabath University, who did not receive any HPV vaccine before.

Of the 378 participants from 2 universities invited to the study, 323 (86\%) responded to the questionnaire. Two participants completed only the demographic questions after they agreed to participate; 2 participants were unable to follow the direction to answer the questionnaire; and 7 participants had missing answers on crucial items. This resulted in 248 tentative participants. Thirty-six participants either had acquired the HPV vaccination, or were uncertain about their HPV vaccination status; and 21 preferred not to answer the history of the HPV vaccine. Accordingly, 191 participants were eligible for final analysis in this research.

\section{Measures}

The questionnaires were initially developed in English, modified from several prior research and translated with permission. Translation of the instruments into Thai and back to English was completed by experts fluent in Thai and English. The back translation version was finally compared to the original version. Moreover, the content validity of the questionnaires was evaluated by multidisciplinary experts (i.e., gynecologist, pharmacist, and health behavior researchers). The content validity of the individual items and overall scale of the questionnaire constructs were shown to be 1.00 .

Additionally, a pilot study was performed on 30 students from the non-health science programs to test for internal reliability of the developed questionnaires. An acceptable coefficient alpha of 0.70 was established [28]. The inter-item correlation was considered as an acceptable range if it was not lower than 0.20 for all pairs of items [29]. The constructs that were found to be significantly associated with the intention to obtain HPV vaccine in earlier studies were included. This research focused on the use of the 3 direct constructs of TPB, with additional constructs from HBM and PMT.

Table 1 Cronbach's alpha or Kuder-Richardson 20 (KR-20) for each construct.

\begin{tabular}{lc}
\hline Constructs & Internal consistency coefficient \\
\hline Attitude to obtain HPV vaccination & $0.93^{\mathrm{a}}$ \\
Subjective norm to obtain HPV vaccination & $0.87^{\mathrm{a}}$ \\
Perceived behavioral control to obtain HPV vaccination & $0.89^{\mathrm{a}}$ \\
Perceived susceptibility to not obtaining HPV vaccination & $0.92^{\mathrm{a}}$ \\
Perceived vaccine effectiveness & $0.91^{\mathrm{a}}$ \\
Cost of HPV vaccination & $0.88^{\mathrm{a}}$ \\
Knowledge of HPV and cervical cancer & $0.71^{\mathrm{b}}$ \\
Intention to obtain HPV vaccine & $-{ }^{\mathrm{c}}$
\end{tabular}

Note: ${ }^{a}$ Cronbach's alpha coefficient; ${ }^{\text {b}}$ Kuder-Richardson 20 (KR-20); ${ }^{\mathrm{c}}$ Construct was not assessed for internal consistency. 
The final 38-items questionnaire included 8 constructs: 1) attitude to obtain HPV vaccination, 2) subjective norm to obtain HPV vaccination, 3) perceived behavioral control to obtain HPV vaccination, 4) perceived susceptibility in not obtaining HPV vaccination, 5) perceived vaccine effectiveness, 6) cost of HPV vaccination, 7) knowledge of HPV and cervical cancer, and 8) intention to obtain HPV vaccination. Participants were also asked about demographic characteristics (11 items), HPV and HPV vaccine awareness ( 2 yes/no items), sexual health information (12 items) and questions about additional recommendations (3 items). Cronbach's alpha or Kuder-Richardson 20 (KR-20) for each construct are shown in Table 1.

\section{Definitions}

Participants answered on a continuous 7-points Likert scale ranging from 1 (strongly disagree) to 7 (strongly agree), excluding the questionnaire of knowledge of HPV and cervical cancer. Participants rated using yes/no/don't know answer choices. The attitude to obtain HPV vaccination was assessed with 6 items which were modified from a previous study [24]. Subjective norm to obtain HPV vaccination was assessed with 6 items modified from previous studies [30,31]. Perceived behavioral control to obtain HPV vaccination was assessed with 4 items modified from a previous study [22]. Perceived susceptibility to not obtaining HPV was assessed with 3 items modified from previous study [26]. Perceived vaccine effectiveness was assessed with 4 items modified from a previous study [22]. Cost of HPV vaccination was assessed with 4 items modified from previous research [17,26,27]. Knowledge of HPV and cervical cancer was assessed with 9 items modified from previous research [19]. Intention to obtain HPV vaccination was assessed with 2 items modified from previous research [8]. Participants with intention score below the mean were categorized as low intention, meanwhile, those with intention score above the mean were categorized as high intention.

\section{Procedures}

Upon the issuance of the permit for data collection in two universities, a request to involve in the investigation was announced through the secretariat of each faculty. The researcher asked the staff to identify the student who met the inclusion criteria and arranged the schedule with them. The researcher or research assistant recruited participants using convenience sampling technique and explained the research purpose on 92 participants from 3 faculties in PSU and 286 participants from 5 faculties in SKRU. The information for participants and consent forms were provided along with the questionnaire. All participants gave their written informed consent. Participants who were not willing to participate were instructed to return all instruments. No participants received any compensation for their part in this research. Data collection was conducted from October to November 2018.

\section{Data analysis}

The demographic characteristics, HPV and HPV vaccine awareness, sexual health information and additional recommendations were assessed using descriptive analysis and presented subsequently. Meanbased splitting was applied to differentiate 2 levels of intention. Several tests were conducted to compare the characteristics of women with a low level of intention and those with a high level. All statistical analysis was conducted using a computer program. Prior to multiple linear regression analysis, assumption testing was conducted to ensure that the predictor and outcome variables were normally distributed, predictors had the same variance, predictors were not correlated with each other and the residual were not correlated [32,33].

The assumption of normality of all variables was checked using Fisher's measures of skewness and kurtosis [33]. An absolute value above 3.29 indicated a non-normal distribution, significant at $\mathrm{p}<0.001$ [32]. Pearson product-moment correlations should be less than 0.70 to indicate that there were no perfect linear relationships between the predictor variables [34]. Additionally, the variance inflation factor (VIF) and tolerance were calculated for each of the covariates in the multivariate model. The VIF and tolerance should be less than 10 and more than 0.10 , respectively [32]. The independent errors assumption was tested with a Durbin-Watson test, in which a value of 2 means that the residuals are not correlated [32]. 
http://wjst.wu.ac.th

The homoscedasticity assumption was checked through the scatter plot of standardized residuals and standardized predicted values [32].

Pearson's coefficient was used to identify the significant correlations among predictor variables that employed an interval scale with the outcome variable or the intention to obtain HPV vaccination. The predictor variables employing an interval scale were attitude to obtain HPV vaccination, subjective norm to obtain HPV vaccination, perceived behavioral control to obtain HPV vaccination, perceived susceptibility to not obtaining HPV vaccination, perceived vaccine effectiveness, and the cost of HPV vaccination. The point-biserial correlation was used to assess the significant correlation between knowledge of HPV and cervical cancer and intention to obtain HPV vaccination. Finally, in accordance with the principal of entry method for multiple regression, all variables were simultaneously entered into the model [32]. Variables that significantly predicted the intention to obtain HPV vaccination were entered once again to find the contribution for each variable on the variance of intention to obtain HPV vaccination in the $2^{\text {nd }}$ model.

\section{Results and discussion}

\section{Results}

Participant characteristics and recommendations

The participant characteristics described include demographic characteristics, family cancer history and personal sexual history, while recommendations encompassed the media platform and educator preferred by participants. Several statistical analyses indicated that the level of intention was significantly associated with monthly allowance from family $(p=0.027)$, religion $(p=0.049)$, father's highest educational level $(p=0.006)$ and awareness of HPV vaccine $(p=0.029)$ (Table 2).

Table 2 Women's characteristic by level of intention $(\mathrm{N}=191)^{*}$.

\begin{tabular}{|c|c|c|c|c|c|}
\hline Demographic Characteristics & \multicolumn{2}{|c|}{ Low intention } & \multicolumn{2}{|c|}{ High intention } & $p$-value \\
\hline Age, M (SD) ${ }^{\mathrm{a}}$ & 20.40 & $(1.35)$ & 20.31 & $(1.44)$ & 0.671 \\
\hline Allowance from family $(\mathrm{N}=181), \mathrm{M}(\mathrm{SD})^{\mathrm{b}}$ & $4,488.66$ & $(2,333.00)$ & $5,097.62$ & $(2,636.26)$ & 0.027 \\
\hline Religion $^{c}$ & 105 & $(55.00 \%)$ & 86 & $(45.00 \%)$ & \\
\hline Buddhist & 61 & $(31.94 \%)$ & 64 & $(33.51 \%)$ & 0.049 \\
\hline Muslim & 43 & $(22.51 \%)$ & 22 & $(11.52 \%)$ & \\
\hline Christian & 1 & $(0.52 \%)$ & 0 & $(0.00 \%)$ & \\
\hline Family income $(\mathrm{N}=186)^{\mathrm{c}}$ & 102 & $(54.84 \%)$ & 84 & $(45.16 \%)$ & \\
\hline$<15,000 \mathrm{THB}$ & 38 & $(20.43 \%)$ & 22 & $(11.83 \%)$ & 0.250 \\
\hline 15,000 - 19,999 ТНВ & 30 & $(16.13 \%)$ & 25 & $(13.44 \%)$ & \\
\hline $20,000-29,999$ ТНВ & 9 & $(4.84 \%)$ & 11 & $(5.91 \%)$ & \\
\hline 30,000 - 39,999 ТНВ & 11 & $(5.91 \%)$ & 10 & $(5.38 \%)$ & \\
\hline 40,000 - 49,999 ТНВ & 8 & $(4.30 \%)$ & 4 & $(2.15 \%)$ & \\
\hline$>50,000 \mathrm{THB}$ & 6 & $(3.23 \%)$ & 12 & $(6.45 \%)$ & \\
\hline Father's occupation $(\mathrm{N}=183)^{\mathrm{c}}$ & 102 & $(55.74 \%)$ & 81 & $(44.26 \%)$ & \\
\hline Business owner & 15 & $(8.20 \%)$ & 16 & $(8.74 \%)$ & 0.514 \\
\hline Governmental employee & 13 & $(7.10 \%)$ & 16 & $(8.74 \%)$ & \\
\hline Company employee & 2 & $(1.09 \%)$ & 1 & $(0.55 \%)$ & \\
\hline Laborer & 31 & $(16.94 \%)$ & 16 & $(8.74 \%)$ & \\
\hline Farmer/ Fisherman & 30 & $(16.39 \%)$ & 24 & $(13.11 \%)$ & \\
\hline Other & 11 & $(6.01 \%)$ & 8 & $(4.37 \%)$ & \\
\hline
\end{tabular}


http://wjst.wu.ac.th

\begin{tabular}{|c|c|c|c|c|c|}
\hline Demographic Characteristics & \multicolumn{2}{|c|}{ Low intention } & \multicolumn{2}{|c|}{ High intention } & \multirow[t]{2}{*}{$p$-value } \\
\hline Mother's occupation $(\mathrm{N}=182)^{\mathrm{c}}$ & 99 & $(54.40 \%)$ & 83 & $(45.60 \%)$ & \\
\hline Housewife & 28 & $(15.38 \%)$ & 25 & $(13.74 \%)$ & 0.855 \\
\hline Business owner & 10 & $(5.49 \%)$ & 8 & $(4.40 \%)$ & \\
\hline Governmental employee & 8 & $(4.40 \%)$ & 8 & $(4.40 \%)$ & \\
\hline Company employee & 3 & $(1.65 \%)$ & 3 & $(1.65 \%)$ & \\
\hline Laborer & 18 & $(9.89 \%)$ & 18 & $(9.89 \%)$ & \\
\hline Farmer/ Fisherman & 23 & $(12.64 \%)$ & 18 & $(9.89 \%)$ & \\
\hline Other & 9 & $(4.95 \%)$ & 3 & $(1.65 \%)$ & \\
\hline Father's highest educational level $(\mathrm{N}=182)^{\mathrm{c}}$ & 99 & $(54.40 \%)$ & 83 & $(45.60 \%)$ & \\
\hline Senior high school & 46 & $(25.27 \%)$ & 32 & $(17.58 \%)$ & 0.006 \\
\hline Vocational/ technical certificate & 18 & $(9.89 \%)$ & 19 & $(10.44 \%)$ & \\
\hline Bachelor's degree & 8 & $(4.40 \%)$ & 20 & $(10.99 \%)$ & \\
\hline Master's degree & 5 & $(2.75 \%)$ & 0 & $(0.00 \%)$ & \\
\hline Other & 22 & $(12.09 \%)$ & 12 & $(6.59 \%)$ & \\
\hline Mother's highest educational level $(\mathrm{N}=183)^{\mathrm{c}}$ & 100 & $(54.64 \%)$ & 83 & $(45.36 \%)$ & \\
\hline Senior high school & 50 & $(27.32 \%)$ & 46 & $(25.14 \%)$ & 0.404 \\
\hline Vocational/ technical certificate & 16 & $(8.74 \%)$ & 14 & $(7.65 \%)$ & \\
\hline Bachelor's degree & 9 & $(4.92 \%)$ & 12 & $(6.56 \%)$ & \\
\hline Master's degree & 3 & $(1.64 \%)$ & 1 & $(0.55 \%)$ & \\
\hline $\mathrm{PhD}$ degree & 1 & $(0.55 \%)$ & 0 & $(0.00 \%)$ & \\
\hline Other & 21 & $(11.48 \%)$ & 10 & $(5.46 \%)$ & \\
\hline Health insurance $^{c}$ & 105 & $(54.97 \%)$ & 86 & $(45.03 \%)$ & \\
\hline Have & 42 & $(21.99 \%)$ & 40 & $(20.94 \%)$ & 0.366 \\
\hline Do not have & 63 & $(32.98 \%)$ & 46 & $(24.08 \%)$ & \\
\hline Universal health coverage $^{c}$ & 105 & $(54.97 \%)$ & 86 & $(45.03 \%)$ & \\
\hline Have & 81 & $(42.41 \%)$ & 68 & $(35.60 \%)$ & 0.749 \\
\hline Do not have & 24 & $(12.57 \%)$ & 18 & $(9.42 \%)$ & \\
\hline University health coverage ${ }^{c}$ & 105 & $(54.97 \%)$ & 86 & $(45.03 \%)$ & \\
\hline Have & 94 & $(49.21 \%)$ & 79 & $(41.36 \%)$ & 0.582 \\
\hline Do not have & 11 & $(5.76 \%)$ & 7 & $(3.66 \%)$ & \\
\hline Smoking history ${ }^{\mathrm{d}}$ & 105 & $(54.97 \%)$ & 86 & $(45.03 \%)$ & \\
\hline Yes & 3 & $(1.57 \%)$ & 1 & $(0.52 \%)$ & 0.629 \\
\hline No & 102 & $(53.40 \%)$ & 85 & $(44.50 \%)$ & \\
\hline Ever heard of HPV ${ }^{c}$ & 105 & $(54.97 \%)$ & 86 & $(45.03 \%)$ & \\
\hline Yes & 56 & $(29.32 \%)$ & 56 & $(29.32 \%)$ & 0.100 \\
\hline No & 49 & $(25.65 \%)$ & 30 & $(15.71 \%)$ & \\
\hline Ever heard of HPV vaccine $(N=190)^{c}$ & 104 & $(54.74 \%)$ & 86 & $(45.26 \%)$ & \\
\hline Yes & 76 & $(40.00 \%)$ & 74 & $(38.95 \%)$ & 0.029 \\
\hline No & 28 & $(14.74 \%)$ & 12 & $(6.32 \%)$ & \\
\hline Family history of gynecological tumor ${ }^{\mathrm{d}}$ & 105 & $(54.97 \%)$ & 86 & $(45.03 \%)$ & \\
\hline Yes & 2 & $(1.05 \%)$ & 3 & $(1.57 \%)$ & 0.659 \\
\hline No & 103 & $(53.93 \%)$ & 83 & $(43.46 \%)$ & \\
\hline Family history of cervical cancer ${ }^{\mathrm{d}}$ & 105 & $(54.97 \%)$ & 86 & $(45.03 \%)$ & \\
\hline Yes & 3 & $(1.57 \%)$ & 2 & $(1.05 \%)$ & 1 \\
\hline
\end{tabular}


http://wjst.wu.ac.th

\begin{tabular}{|c|c|c|c|c|c|}
\hline Demographic Characteristics & \multicolumn{2}{|c|}{ Low intention } & \multicolumn{2}{|c|}{ High intention } & $p$-value \\
\hline No & 102 & $(53.40 \%)$ & 84 & $(43.98 \%)$ & \\
\hline Marital status ${ }^{c}$ & 105 & $(54.97 \%)$ & 86 & $(45.03 \%)$ & \\
\hline Have partner & 7 & $(3.66 \%)$ & 11 & $(5.76 \%)$ & 0.150 \\
\hline Single & 98 & $(51.31 \%)$ & 75 & $(39.27 \%)$ & \\
\hline Sexual orientation $(\mathrm{N}=190)^{\mathrm{c}}$ & 104 & $(54.74 \%)$ & 86 & $(45.26 \%)$ & \\
\hline Heterosexual & 92 & $(48.42 \%)$ & 77 & $(40.53 \%)$ & 0.198 \\
\hline Homosexual & 8 & $(4.21 \%)$ & 2 & $(1.05 \%)$ & \\
\hline Bisexual & 4 & $(2.11 \%)$ & 6 & $(3.16 \%)$ & \\
\hline Other & 0 & $(0.00 \%)$ & 1 & $(0.53 \%)$ & \\
\hline PAP experience ${ }^{d}$ & 105 & $(54.97 \%)$ & 86 & $(45.03 \%)$ & \\
\hline Yes & 1 & $(0.52 \%)$ & 0 & $(0.00 \%)$ & 1 \\
\hline No & 104 & $(54.45 \%)$ & 86 & $(45.03 \%)$ & \\
\hline Sexual intercourse ${ }^{c}$ & 105 & $(54.97 \%)$ & 86 & $(45.03 \%)$ & \\
\hline Ever & 8 & $(4.19 \%)$ & 10 & $(5.24 \%)$ & 0.345 \\
\hline Never & 97 & $(50.79 \%)$ & 76 & $(39.79 \%)$ & \\
\hline
\end{tabular}

Note: ${ }^{*}$ The number of participants $(N)$ varies since participants accidentally skipped questions or chose not to answer; ${ }^{a}$ Independent sample T-test; ${ }^{b}$ Mann-Whitney U, ${ }^{\mathrm{c}}$ Chi-square test, ${ }^{\mathrm{d}}$ Fisher's Exact Test.

\section{Demographic characteristics}

Table 2 provides the participant demographic characteristics. The participants' mean age was 20.36 years $(\mathrm{SD}=1.39)$. The average mean monthly allowance of 181 reporting students was 4,771.27 THB ( $\mathrm{SD}=2,490.04)$ or 115.92 USD. Consequently, the participant's monthly allowance is not enough to purchase the vaccine, since the vaccines are offered at total expense starting from 6,200 THB or 202.4 USD. Most participants were Buddhist (65.45\%). Of 186 participants reporting their family income, $32.26 \%$ reported a family income less than 15,000 THB.

Parental occupation questions revealed $39.51 \%$ of father's occupation were farmer or fisherman and $29.12 \%$ of mothers were housewives. Parental education questions showed that $42.86 \%$ of fathers and $52.46 \%$ of mothers had graduated from senior high school. While only $42.93 \%$ of the participants had health insurance, $78.01 \%$ had universal health coverage and $90.58 \%$ of them had university health coverage. Normally, university health coverage and universal health coverage do not provide coverage for the HPV vaccine. $42.93 \%$ of the participants stated that coverage of HPV vaccine is offered by some health insurance carriers, depending on the insurance package chosen by the participants. Most of the participants $(97.91 \%)$ did not have a history of smoking. Of the 191 participants, $112(58.64 \%)$ had heard about HPV and 151 (78.95\%) had heard about the HPV vaccine.

\section{Family's cancer history and personal sexual history}

Table 2 provide the participants family cancer history. Among 191 participants, 5 (2.62 \%) reported a family history of gynecological tumors, 5 (2.62 \%) reported a family history of cervical cancer and only 1 participant had ever been screened by a PAP smear. The majority of the participants were single $(90.58$ $\%)$. Of the 190 participants who reported their sexual orientation, $169(88.95 \%)$ self-identified as heterosexual and $18(9.42 \%)$ had a history of sexual intercourse.

\section{Media platform and educator}

Out of 191 participants, 145 (75.92 \%) agreed that Facebook was the best media platform for HPV vaccine promotion. Other platforms were websites, 117 (61.26\%); television, 99 (51.83 \%); brochures, 
47 (24.61 \%); and others, including Line, Twitter, Instagram and Short Message Service (SMS), 9 (4.71\%). Of the 191 participants, $180(94.24 \%)$ agreed that doctors are reliable educators for the HPV vaccine, followed by nurses, 119 (62.30\%), vaccinated women, 99 (51.83\%), lecturers, 90 (47.12\%), and others, $3(1.57 \%)$.

\section{Predictors of intention to obtain the vaccine of HPV}

HPV vaccination intention was significantly and positively correlated with attitude to obtain HPV vaccination, subjective norm to obtain HPV vaccination, perceived behavioral control to obtain HPV vaccination, perceived susceptibility in not obtaining HPV vaccination and perceived vaccine effectiveness. However, the intention to obtain HPV vaccine was not significantly correlated with the cost of HPV vaccination or knowledge of HPV vaccine and cervical cancer.

The Z-score for the skewness of attitude to obtain the HPV vaccine generated an absolute value of 4.67 , indicating a significant pile-up of scores on the right of the distribution at $p<0.001$. As a consequence, participants' attitude to obtain the HPV vaccination was categorized into high and low levels. Multicollinearity diagnostics including Pearson-product moment correlation, VIF and tolerance, indicated that the predictor variables were not strongly correlated. The assumption of Durbin-Watson test was likely to be met as the result was 1.797 . There was no funnel pattern on the scatter plot of standardized residual and standardized predicted value, indicating that the assumption of homoscedasticity had been met.

Table 3 Multiple regression analysis of predicting the intention to obtain HPV vaccine $\left(\mathrm{N}=172^{\mathrm{a}}\right)$.

\begin{tabular}{|c|c|c|c|c|c|}
\hline Variables & B & SEB & $\boldsymbol{\beta}$ & $\mathbf{R}^{2}$ & Adjusted $\mathbf{R}^{2}$ \\
\hline Model 1 & & & & 0.42 & 0.41 \\
\hline Constant & 2.97 & 0.97 & & & \\
\hline $\begin{array}{l}\text { Perceived behavioral control to obtain HPV } \\
\text { vaccination }\end{array}$ & 0.12 & 0.04 & $0.22^{* *}$ & & \\
\hline Attitude to obtain HPV vaccination & 1.31 & 0.39 & $0.24^{* *}$ & & \\
\hline Subjective norm to obtain HPV vaccination & 0.04 & 0.03 & 0.11 & & \\
\hline Perceived vaccine effectiveness & 0.09 & 0.04 & 0.16 & & \\
\hline $\begin{array}{l}\text { Perceived susceptibility to not obtaining HPV } \\
\text { vaccination }\end{array}$ & 0.10 & 0.04 & $0.17^{*}$ & & \\
\hline Model 2 & & & & 0.40 & 0.39 \\
\hline Constant & 4.70 & 0.66 & & & \\
\hline Attitude to obtain HPV vaccination & 1.70 & 0.36 & $0.31^{* * *}$ & & \\
\hline $\begin{array}{l}\text { Perceived behavioral control to obtain HPV } \\
\text { vaccination }\end{array}$ & 0.16 & 0.04 & $0.31^{* * *}$ & & \\
\hline $\begin{array}{l}\text { Perceived susceptibility to not obtaining HPV } \\
\text { vaccination }\end{array}$ & 0.12 & 0.04 & $0.22^{* *}$ & & \\
\hline
\end{tabular}

Note: ${ }^{a}$ Eleven multivariate outliers were detected by Mahalanobis test $\left(\chi^{2}>11.070, \mathrm{df}=5, p=0.05\right)$. Ten influential cases were detected by Cook's distance ( $\mathrm{Di} \geq 4 / \mathrm{n}-(\mathrm{k}+1), \mathrm{k}=5, \mathrm{n}=191)$. Two same cases showed up in both tests; thus 19 cases were excluded and 172 cases were used in multiple regression analysis; ${ }^{*} p<0.05 ;{ }^{* *} p=0.005 ;{ }^{* * *} p<0.001$.

When 5 predictor variables were included in the multiple regression model, significant $(p<0.001)$ improvement of $\mathrm{R}^{2}$ by 0.42 and F-ratio of 24.39 was obtained. Three significant predictors identified from the $1^{\text {st }}$ model were 1) attitude to obtain HPV vaccination, 2) perceived behavioral control to obtain HPV vaccination and 3 ) perceived susceptibility to not obtaining HPV vaccination. The $2^{\text {nd }}$ model indicated 
that these 3 predictors accounted for $40 \%$ of the variance in intention to obtain the HPV vaccine: $\mathrm{F}$ $(3,168)=37.46, p<0.001$ (Table 3). Table 3 suggest that the odds of obtain HPV vaccine increase when Thai female college students were having more positive attitude to obtain HPV vaccination, perceived behavioral control to obtain HPV vaccination and perceived susceptibility to not obtaining HPV vaccination. The predictors of intention to obtain the HPV vaccine found in this study are illustrated in Figure 1.

The post hoc power analysis has shown that actual Cohen effect size did not align with the expected effect size. Nevertheless, based on Cohen's rules of thumb, the actual effect (0.669) could be categorized as large effect size. The probability of finding true significance was 1.00 ; therefore, the probability of a Type II error was 0 .

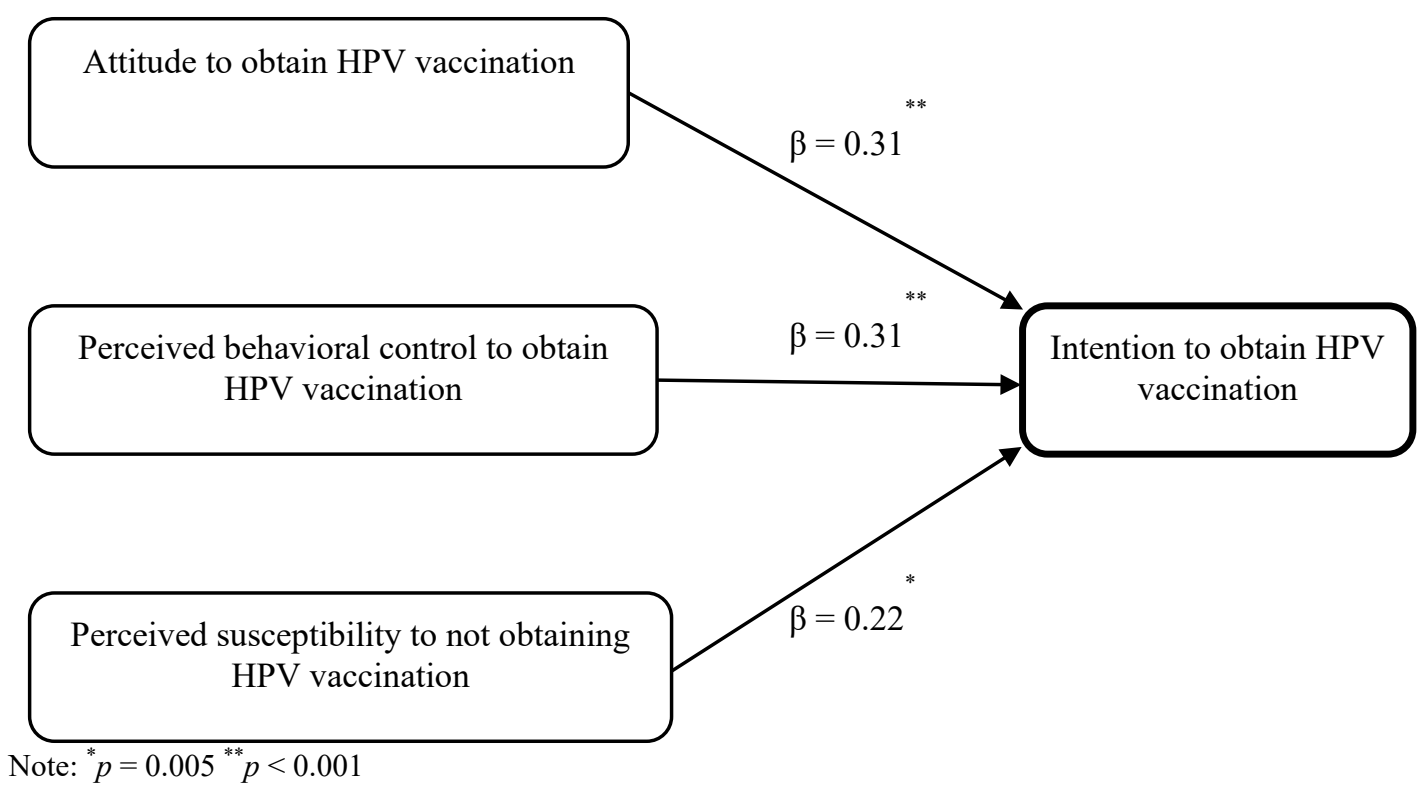

Figure 1 Best predictive multiple regression model for intention to obtain vaccine of HPV.

\section{Discussion}

Several characteristics were significantly different between high intention and low intention. Monthly allowance from family was found to be different between the two groups, even though parental income was not different. This result was consistent with a prior study among Thai female college students showing no differences in parental income between the two intention levels [35].

Furthermore, current findings appear to be in line with a prior study among college women in Chiang Mai, which propounded the view that the participants' level of intention is associated with the awareness of the HPV vaccine [19]. More than 3 quarters of the Thai female college students in this study had heard of the HPV vaccine. However, the percentage of those who have heard about the HPV vaccine among those with low intention was slightly higher than that among those with high intention. This may be due to insufficient information about the vaccine, even though the HPV vaccine has been introduced for approximately 9 years in Thailand. In addition, although the government has included the HPV vaccine as a national mandatory vaccine, their program only targets $5^{\text {th }}$ grade students [11]. In depth information regarding the HPV vaccine for the population outside the target population of immunization programs is indispensable. Another possible explanation is that women's reluctance to vaccinate might be 
related to their belief in the effectiveness of HPV vaccine [22]. Thus, sufficient information regarding the vaccine efficacy is needed [36].

These findings also highlight the influence of religion on young women's thought about the HPV vaccine [37]. Religion is a complex factor, and specific religious perspectives about vaccines are presumably different. Although the majority of Thais are Buddhist, there is a substantial Muslim population in the southern Thailand. In this study, about a third of the study population was Muslim, and $66.15 \%$ had high intention to vaccinate. In contrast, only $51.20 \%$ of the Buddhist population in this study had high intention.

Additionally, the findings from this study provide insight into the father's educational background as an influencing factor on the level of intention of their daughter to obtain the HPV vaccine. However, the mother's educational level in this study was not related to the level of intention among Thai female college students. Unlike the aforementioned result, studies from Norway and Sweden showed the opposite where the maternal university education level was more strongly associated with HPV vaccination status outcome than paternal university education level $[38,39]$.

This inconsistency in the findings could be moderated by cultural practice. Thai mothers tend to be the main caretakers in the family compared to fathers [30]. However, a possible explanation for the result might be that Thai fathers were more likely to receive more support from other family members for encouraging their daughters than for encouraging their sons [41]. Moreover, Thai fathers reported they were warmer to daughters than sons [42]. This finding might help to understand the importance of a fathers' role in their daughters' development among Thais.

As the father plays an important part in his daughters' intention to obtain HPV vaccine, hence, it could be assumed that his attitude regarding the safety of HPV vaccine for the daughter serves as one of the main concerns. Across several previous studies, parental attitudes regarding child safety have been reported to be among the determinants of parents' decision to obtain the HPV vaccine for their children [43]. Parents with concerns about the safety of the HPV vaccine negatively affected the daughters' uptake of the HPV vaccine, whereas parents who perceived the HPV vaccine as beneficial had a positive effect on their daughters' uptake of HPV vaccine [43]. These findings suggest providing parents with information about the safety and the importance of the HPV vaccine in order to increase their positive attitude, thus increasing their willingness to explain the benefits of HPV vaccines to their daughters.

The lack of association observed between maternal education level and level of intention was opposite to earlier data from Norway or Sweden [38,39] which seemed to depend on the mother's level of education and youth-parent relationship. In the current study, almost $70 \%$ of the mothers had an education level of senior high school or lower. Highly educated parents could play active roles in their daughter's decision to vaccinate, as observed in the earlier study in Norway [38], while less educated parents seem more passive about their daughters' decisions concerning vaccination. Well-educated mothers have more confidence interacting in health care settings [43]. Well-educated mothers have better communication skills, which has a strong association with children's full immunization [43]. Moreover, a previous study showed that mothers tend to hold the majority of responsibility in child care, while the involvement of the father in child care appears to be low [42]. Daughters also described a warm or close relationship with their fathers. These might be attributed to the lack of relationship between the level of intention of the HPV vaccination in these Thai female college students and maternal education. It seems that an alternative moderation pathway is needed to involve mothers in their child's immunization decision. Prior research suggests the importance of increasing basic medical knowledge as a beneficial route to elevate children's immunization rate despite the mother educational level [44].

This research set out to evaluate predictors of intention to obtain the HPV vaccination in Thai female college students studying in non-health science programs. It is interesting to note that among 7 expected predictors, 5 predictors from the TPB, HBM and PMT were correlated with vaccination intention, including attitude to obtain HPV vaccination, subjective norm to obtain HPV vaccination, perceived behavioral control to obtain HPV vaccination, perceived susceptibility to not obtaining HPV vaccination and perceived vaccine effectiveness. These results were supported by those mentioned in several prior studies 
In the $2^{\text {nd }}$ multiple regression model, three predictors found to be significant in the $1^{\text {st }}$ model, which were included and explained $40 \%$ of the variances in Thai female college students' intention. The number of variance found was in agreement with the earlier meta-analysis of the application of TPB on health behavior, in which a predictive value of 0.41 was reported [45]. Further research on the other variables, not included in the current study, is worth exploring.

In the $2^{\text {nd }}$ predictive model, an attitude to obtain the HPV vaccination provided the greatest and most significant total effect on intention to obtain the vaccine of HPV. This may be due to a woman's feelings that the HPV vaccine is useful, favorable, safe, pleasing, and desirable. This result seems consistent with Ratanasiripong [8], who recommended an intervention to increase favorable attitude to obtain the HPV vaccination in order to increase intention. Interestingly, this study revealed that perceived behavioral control to obtain HPV vaccination was the $2^{\text {nd }}$ strongest predictor of intention in obtaining HPV vaccination. Having intention to receive the HPV vaccination was triggered by Thai female college students' perception that they had full control over obtaining the vaccine. These findings may be attributed to participants' independent feelings. Yet, these findings conflict with several studies which reported that perceived behavioral control to obtain the HPV vaccination did not significantly contribute to the final model $[8,23,30]$. Therefore, this finding suggests another significant construct in TPB, despite the aforementioned insignificant or weak association with intention. Theoretically, it was evident that the actual control over behavior determines the intention to obtain the HPV vaccination. The result of this study indicates the importance of employing TPB framework in finding the predictors in the vaccination behavior. It is suggested that intervention should be focused on increasing Thai female college students' perceived behavioral control to enhance both intention and vaccination behavior. This is in accordance with the claim by Ajzen [46], who proposed that when perceived behavioral control is strong, any favorable intention would be able to emerge as a behavior.

Another important finding highlighted in the $2^{\text {nd }}$ model was that perceived susceptibility to not obtaining the HPV vaccination was found to be a significant predictor of intention to obtain HPV vaccination. This is an HBM construct, which significantly predicts the intention to obtain HPV vaccination. When Thai female college students perceive a likelihood of contracting genital HPV, cervical cancer and genital warts, they tend to get vaccinated and have a higher expectation to obtain the HPV vaccination. A prior study revealed similar findings that when TPB and HBM were employed, perceived susceptibility was the only HBM construct that significantly predicted intention to obtain HPV vaccination [30]. Moreover, this study indicates the moderate capability of TPB in determining the predictors for intention of vaccination behavior, while HBM offers limited capacity in determining the predictors of this behavior.

The results of this study did not detect a significant predictive ability of perceived vaccine effectiveness toward intention to obtain HPV vaccination in the $2^{\text {nd }}$ model. Thai female college students' decision-making process to obtain the HPV vaccination was not influenced by their belief in the effectiveness of the HPV vaccine. Even though the participants were familiar with the HPV vaccine, they might have had insufficient understanding or knowledge of the effectiveness of the HPV vaccine. In fact, the HPV vaccine was not fully covered for the target population at the time this study was conducted. It is somewhat surprising that these findings were in contrast to the findings by Gainforth et al., which conducted the study in Canadian college women [22]. The variation in findings between Thailand and Canada may be attributed to the release date of the HPV vaccine, where HPV vaccine was introduced in Canada earlier than Thailand.

An unanticipated finding was that the subjective norm to obtain HPV vaccination was the only TPB construct which was unable to significantly predict the intention to obtain the HPV vaccination. This may be explained by the fact that Thai female college students' intention to obtain the HPV vaccination is largely a personal decision, rather than on the approval of a boyfriend or girlfriend, parents, best friends, teachers, public health nurse or physician. This result differs from some published studies that repeatedly suggest that the subjective norm was a significant predictor of intention to get HPV vaccination among undergraduate women in the US [23,24,26,30]. Yet, this contradictory result may be due to the nature of the subjective norm. The subjective norm is a social factor which was based on normative beliefs [16]. Normative factors play a different role in different cultural contexts [47]. In the US, undergraduate 
women's perceptions are affected by their significant others' perceptions of the HPV vaccination. Thai society is relatively more collective than the US culturally speaking [48]. In Thailand, cultural norms regarding preferable behavior exert a greater influence than social pressure from significant others.

\section{Limitations}

There are some research limitations which should be noted in this study. First, this study comprises a relatively small and convenience sample, limiting the generalization of the findings to a larger population of Thai female college students, a country of 76 provinces with diverse cultural and religious backgrounds. Secondly, the measurement was a self-administered questionnaire, hence generating an overestimation of the answers on their beliefs. Third, participants may have been reluctant to provide truthful answers for questions relating to sexual health practice, since sex is considered an inappropriate subject to discuss openly in Thai culture. Fourth, a decent-sized number of participants indicated either uncertainty or unwillingness to answer the vaccination status, yet the answer was not verified.

\section{Conclusions}

This research contributes new information on factors that predict the intention to obtain HPV vaccination among Thai female college students enrolled in non-health science programs. The findings of this study suggest that Thai female college students believe that they would plan or expect to obtain the HPV vaccination if they had the confidence to obtain HPV vaccination and to overcome obstacles that prevent them from obtaining HPV vaccination. The intention can be predicted by attitude to obtain HPV vaccination. The intention can also be predicted by perceived susceptibility to not obtaining HPV vaccination. An intervention to increase the intention to obtain HPV vaccination should focus on attitude to obtain HPV vaccination, perceived behavioral control to obtain HPV vaccination and perceived susceptibility to not obtaining HPV vaccination by specifically designing promotional or educational material for Thai female college students. The intervention should be focused on Facebook, websites, and TV advertising which Thai female college students most prefer to deliver the promotion or information about the HPV vaccination. In the university setting, student health care centers might take the initiative to obtain the vaccination data through the mandatory filling of vaccination status on the admission of new students. Moreover, a survey on the university mailing list or social media groups might be effective in identifying enrolled unvaccinated students who are interested in catching up.

\section{Acknowledgements}

This work was supported by the Thailand's Education Hub for Southern Region of ASEAN Countries (TEH-AC) under Grant (number TEH-AC 090/2016) and Graduate School, Prince of Songkla University, Thailand under Grant (number 6987).

\section{References}

[1] World Health Organization, Available at: http://www.who.int/news-room/fact-sheets/detail/humanpapillomavirus-(hpv)-and-cervical-cancer, accessed March 2019.

[2] L Bruni, LR Barrionuevo, G Albero, B Serrano, M Mena, D Gómez, J Muñoz, FX Bosch and SD Sanjosé. Human papillomavirus and related disease in Thailand, ICO/IARC Information Centre on HPV and Cancer (HPV Information Centre), Barcelona, 2018.

[3] R Hull, M Mbele, T Makhafola, C Hicks, S-M Wang, RM Reis, R Mehrotra, Z Mkhize-Kwitshana, G Kibiki, DO Bates and Z Dlamini. Cervical cancer in low and middle-income countries (Review). Oncol. Lett. 2020; 20, 2058-74.

[4] FX Bosch, A Lorincz, N Muñoz, CJLM Meijer and KV Shah. The causal relation between human papillomavirus and cervical cancer. J. Clin. Pathol. 2002; 55, 244-65.

[5] C Suthipintawong, S Siriaunkgul, K Tungsinmunkong, C Pientong, T Ekalaksananan, A Karalak, P Kleebkaow, S Vinyuvat, S Triratanachat, S Khunamornpong and T Chongsuwanich. Human 
http://wjst.wu.ac.th

papilloma virus prevalence, genotype distribution, and pattern of infection in Thai women. Asian Pac. J. Cancer Prev. 2011; 12, 853-6.

[6] N Phoolcharoen, N Kantathavorn, T Sricharunrat, S Saeloo and W Krongthong. A population-based study of cervical cytology findings and human papillomavirus infection in a suburban area of Thailand. Gynecol. Oncol. Rep. 2017; 21, 73-7.

[7] Centers for Disease Control and Prevention (US). Youth risk behavior surveillance: National college health risk behavior survey-United States, 1995. MMWR CDC Surveill. Summ. 1997; 46, 156.

[8] NT Ratanasiripong. 2012, What college women know, think, and do about human papillomavirus (HPV) and HPV vaccine. Ph. D. Dissertation. University of Missouri, Missouri, United States.

[9] A Herrera-Ortiz, CJ Conde-Glez, ML Olamendi-Portugal, S Garcia-Cisneros, T Plett-Torres and MA Sanchez-Aleman. College women, HPV genotyping and sexual behavior before HPV vaccination: Results from samples stored for a long time. J. Infect. Publ. Health 2018; 11, 286-9.

[10] AB Moscicki, Y Ma, J Jonte, S Miller-Benningfield, E Hanson, J Jay, CGD Medina, S Farhat, L Clayton and S Shiboski. The role of sexual behavior and human papillomavirus persistence in predicting repeated infections with new human papillomavirus types. Cancer Epidemiol. Biomarkers Prev. 2010; 19, 2055-65.

[11] W Klinsupa, P Pensuk, J Thongluan, S Boonsut, R Tragoolpua, P Yoocharoen and S Jiamsiri. O16.3 HPV vaccine introduction in Thailand. Sex Transm. Infect. 2015; 91, A61.

[12] E Meites, A Kempe, LE Markowitz. Use of a 2-dose schedule for human papillomavirus vaccination - updated recommendations of the advisory committee on immunization practices. Am. J. Transplant. 2017; 17, 834-7.

[13] World Health Organization, Available at: http://www.who.int/immunization/hpv/learn/ comprehensive_cervical_cancer_who_2013.pdf, accessed September 2017.

[14] TA Westra, MH Rozenbaum, RM Rogoza, HW Nijman, T Daemen, MJ Postma and JC Wilschut. Until which age should women be vaccinated against HPV infection? Recommendation based on cost-effectiveness analyses. J. Infect. Dis. 2011; 204, 377-84.

[15] The United Nations Educational, Scientific and Cultural Organization, Available at: http://uis.unesco.org/country/TH, accessed April 2018.

[16] I Ajzen. The theory of planned behavior. Organ. Behav. Hum. Decis. Process. 1991; 50, 179-211.

[17] DA Patel, M Zochowski, S Peterman, AF Dempsey, S Ernst and VK Dalton. Human papillomavirus vaccine intent and uptake among female college students. J. Am. Coll. Health 2012; 60, 151-61.

[18] MA Knudtson. 2017, The effects of a HPV educational intervention aimed at collegiate males on knowledge, vaccine intention and uptake. Ph. D. Evidence-based practice project report. Valparaiso University, Indiana, United States.

[19] P Juntasopeepun, PM Davidson, N Suwan, Y Phianmongkhol and J Srisomboon. Human papillomavirus vaccination intention among young women in Thailand. Asian Pac J Cancer P. 2011; 12, 3213-9.

[20] NT Ratanasiripong, S Sri-Umporn, D Kathalae, S Hanklang and P Ratanasiripong. Human papillomavirus (HPV) vaccination and factors related to intention to obtain the vaccine among young college women in Thailand. J Health Res. 2018; 32, 142-51.

[21] A Borlu, O Gunay, E Balci and M Sagiroglu. Knowledge and attitudes of medical and non-medical Turkish University students about cervical cancer and HPV vaccination. Asian Pac. J. Cancer Prev. 2016; 17, 299-303.

[22] HL Gainforth, W Cao and AE Latimer-Cheung. Determinants of human papillomavirus (HPV) vaccination intent among three Canadian target groups. J. Cancer Educ. 2012; 27, 717-24.

[23] AL Krawczyk, S Perez, E Lau, CA Holcroft, R Amsel, B Knäuper and Z Rosberger. Human papillomavirus vaccination intentions and uptake in college women. Health Psychol. 2012; 31, 68593.

[24] NT Ratanasiripong, AL Cheng and M Enriquez. What college women know, think, and do about human papillomavirus (HPV) and HPV vaccine. Vaccine 2013; 31, 1370-6. 
http://wjst.wu.ac.th

[25] AM Teitelman, M Stringer, GT Nguyen, AL Hanlon, T Averbuch and AW Stimpfel. Social cognitive and clinical factors associated with HPV vaccine initiation among urban, economically disadvantaged women. J. Obstet. Gynecol. Neonatal. Nurs. 2011; 40, 691-701.

[26] MA Gerend and JE Shepherd. Predicting human papillomavirus vaccine uptake in young adult women: Comparing the health belief model and theory of planned behavior. Ann. Behav. Med. 2012; 44, 171-80.

[27] EM Donadiki, R Jimenez-Garcia, V Hernandez-Barrera, P Sourtzi, P Carrasco-Garrido, ALD Andres, I Jimenez-Trujillo and EG Velonakis. Health belief model applied to non-compliance with HPV vaccine among female university students. Publ. Health 2014; 128, 268-73.

[28] JM Cortina. What is coefficient alpha? An examination of theory and applications. J. Appl. Psychol. 1993; 78, 98-104.

[29] RL Piedmont. Inter-item correlations. In: AC Michalos (Ed). Encyclopedia of quality of life and well-being research. Springer Netherlands, Dordrecht, 2014, p. 3303-4.

[30] KK Bennett, JA Buchanan and AD Adams. Social-cognitive predictors of intention to vaccinate against the human papillomavirus in college-age women. J. Soc. Psychol. 2012; 152, 480-92.

[31] MC Wang, CY Chou, MC Ma and YY Hsu. Parental intention regarding the administration of the HPV vaccine for adolescent daughters in Taiwan. Women Health 2016; 56, 361-75.

[32] Field AP. Discovering statistics using SPSS: And sex and drugs and rock ' $n$ ' roll. $3^{\text {th }}$ eds. SAGE Publications, Los Angeles, 2009.

[33] SB Plichta and EA Kelvin. MUNRO'S statistical methods for health care research. $6^{\text {th }}$ eds. Wolters Kluwer Health/Lippincott Williams \& Wilkin, Philadelphia, 2013.

[34] KP Vatcheva, M Lee, JB McCormick and MH Rahbar. Multicollinearity in regression analyses conducted in epidemiologic studies. Epidemiol. Open Access 2016; 6, 227.

[35] M Dany, A Chidiac and AH Nassar. Human papillomavirus vaccination: Assessing knowledge, attitudes, and intentions of college female students in Lebanon, a developing country. Vaccine 2015; 33, 1001-7.

[36] Ratanasiripong NT. 2012, What college women know, think, and do about human papillomavirus (HPV) and HPV vaccine. Ph. D. Dissertation. University of Missouri, Missouri, USA.

[37] J Bodson, A Wilson, EL Warner and D Kepka. Religion and HPV vaccine-related awareness, knowledge, and receipt among insured women aged 18-26 in Utah. PLoS One 2017; 12, e0183725.

[38] B Feiring, I Laake, T Molden, I Cappelen, SE Haberg, P Magnus, ÓA Steingrímsdóttir, BH Strand, J Stålcrantz and L Trogstad. Do parental education and income matter? A nationwide register-based study on HPV vaccine uptake in the school-based immunisation programme in Norway. BMJ Open 2015; 5, e006422.

[39] A Leval, E Herweijer, A Ploner, S Eloranta, JF Simard, J Dillner, C Young, E Netterlid, P Sparén and L Arnheim-Dahlström. Quadrivalent human papillomavirus vaccine effectiveness: A Swedish national cohort study. J. Natl. Cancer Inst. 2013; 105, 469-74.

[40] O Tulananda, DM Young and JL Roopnarine. Thai and American fathers' involvement with preschool-age children. Early Child Dev. Care 2006; 97, 123-33.

[41] NM Punyanunt-Carter. An examination of communication motives and relationship maintenance behaviors in Thai and US father-daughter relationships. Asian Comm. Res. 2016; 13, 157-79.

[42] DL Putnick, MH Bornstein, JE Lansford, L Chang, K Deater-Deckard, LD Giunta, S Gurdal, KA Dodge, PS Malone, P Oburu, C Pastorelli, AT Skinner, E Sorbring, S Tapanya, LMU Tirado, A Zelli, LP Alampay, SM Al-Hassan, D Bacchini and AS Bombi. Agreement in mother and father acceptance-rejection, warmth, and hostility/rejection/neglect of children across nine countries. Cross-Cult. Res. 2012; 46, 191-223.

[43] PA Newman, CH Logie, A Lacombe-Duncan, P Baiden, S Tepjan, C Rubincam, N Doukas and F Asey. Parents' uptake of human papillomavirus vaccines for their children: A systematic review and meta-analysis of observational studies. BMJ Open 2018; 8, e019206.

[44] K Vikram, R Vanneman and S Desai. Linkages between maternal education and childhood immunization in India. Soc. Sci. Med. 2012; 75, 331-9. 
http://wjst.wu.ac.th

[45] G Godin and G Kok. The theory of planned behavior: A review of its applications to health-related behaviors. Am. J. Health Promot. 1996; 11, 87-98.

[46] I Ajzen, Available at: http://people.umass.edu/aizen/tpb.background.html, accessed March 2018.

[47] W Hosking, R Borland, HH Yong, G Fong, M Zanna, F Laux, JThrasher, WB Lee, B Sirirassamee and M Omar. The effects of smoking norms and attitudes on quitting intentions in Malaysia, Thailand and four Western nations: A cross-cultural comparison. Psychol. Health 2009; 24, 95-107.

[48] G Hofstede, GJ Hofstede and M Minkov. Culture and organization: Software of the mind. McGrawHill, London, 1991. 